\title{
UNSTANDARDIZED LCA-BASED TECHNOLOGY SUSTAINABILITY ASSESSMENT FOR ALTERNATIVE ENERGY SCENARIOS FOR COGENERATION SYSTEM
}

doi:10.2478/mape-2018-0099

Date of submission of the article to the Editor: 05/2018 Date of acceptance of the article by the Editor: $07 / 2018$
MAPE 2018, volume 1, issue 1, pp. 785-791

\author{
Dr. Aldona Kluczek \\ Warsaw University of Technology, Poland
}

\begin{abstract}
In pursuit of higher energy savings and de-carbonization, greater fuel diversity and lower pollutant emission is possible by production processes through energy-savings opportunities and associated environmentally-benign technologies. Current production processes represents the biggest consumption of energy, and the greatest amount of emissions emitted to the environment. Improvement in energy efficiency is considered as the basic principle in realizing energy-saving, bringing cost-effective benefits and reduction of greenhouse emissions. Hence, this study proposes a framework to assess alternative sustainability of cogeneration systems, integrating the economic, environmental, and social indicators.

The results showed that the cogeneration system with a new boiler with a 600 PSIG pressure and a new turbine seems to be a cost-efficient solution compared to the baseline scenario saving energy at the level of $1,823,072 \mathrm{kWh} / \mathrm{yr}(63 \%)$ against the baseline scenario. In the case study, the implemented solution in the plant improved the overall sustainability degree of technology by $53 \%$ (from $46 \%$ as baseline to $97 \%$ ).
\end{abstract}

Keywords: LCA, technology assessment, assessment criteria, energy efficiency, cogeneration system

\section{INTRODUCTION}

Manufacturing is one of the most important branches of industry in many countries, especially in well developed ones. However, an increase in productivity, which occupies a key position in the struggle for competitiveness, can only be achieved if efficient use is made of available resources, such as energy, material and personnel. The gap that will arise between the necessary increase in productivity and a growing shortage of resources must be closed by increasing efficiency.

From the methodological point of view, technology, needs to assessment criteria and measurable metrics "at different levels of aggregation, consistent boundaries and allocation concerns related to arising energy consumption and carbon dioxide $\left(\mathrm{CO}_{2}\right)$ emissions indicators" (Armina and Vilsi, 2015; Lindberg at al., 2015). It allows covering set of sustainability indicators integrating environmental, economic and social for assessment of alternative energy technologies scenarios for cogeneration system (or combined heat and power (CHP). Integrated assessment methods based on LCA concentrate on one of both topics only (Skowrońska and Filipek, 2014) or on environmental impacts and cost evaluation (Da Silva et al., 2009), where e.g. the LCA methodologies have all in one way or the other failed to achieve this requirement. Methods developed on the basis of "environment in general" "focus on environmental issues with policy, programme and infrastructure provision and LCA methods attempt to address social and economic issues in addition to environmental concerns.

Although commonly used different sustainability assessment methods used for various application and sectors (Ness et al., 2007), there is a need to evaluate energy sustainability using a streamlined methodology based on technology life cycle thinking and a set of 
composite indicators considering various effects of technology imapct on the environment, the economy and society.

The application of a framework of sustainability assessment of energy technology which integrate various methods: life cycle assessment, life cycle costing, social sustainability assessment and multi-criteria decision analysis in terms of environmental, economic and social issues is described in Santoyo-Castelazo and Azapagic (2014). LCA method is limited to environmental assessment only (Benedetto and Klemes, 2009; Kluczek, 2018). In particular, due to aggregated level of information (energy data), an unstandardized energy LCA-based indicators sustainability assessment approach, has been considered as an LCA-efficient method to fill the research gap (not using experts' knowledge). However, this assessment tool should evolve providing clear information on the magnitude of impacts on technology as the result of specific industrial processes.

The goal of this study is to propose assessment and the potential environmental impact related to cogeneration systems for three scenarios for the treatment of hardwood lumber produced by a company operating in the U.S. through the application of unstandardized Life Cycle Assessment approach, energy LCA in order to find the energy efficient CHP technology.

\section{METHODOLOGY}

Methodology of unstandardized LCA-based technology sustainability assessment for alternative energy scenarios for cogeneration system is described in Fig. 1.

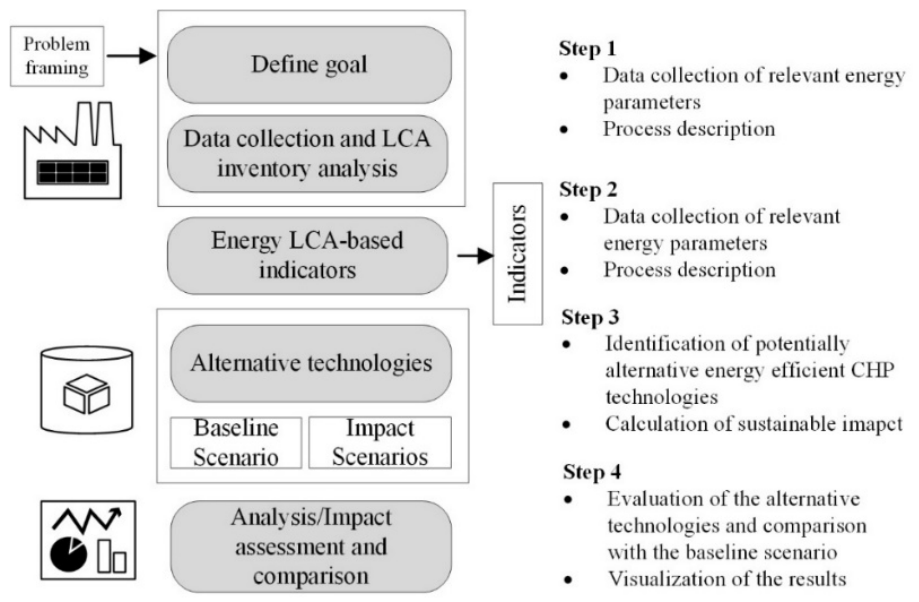

Fig. 1. LCA-based technology sustainability assessment methodology

\subsection{Data collection}

Data collection is build based on monthly energy consumption (utility bills) in the process (see Table 1). The annual energy consumption used up by the facility was determined and amounts to $35,567,274.25 \mathrm{kWh} / \mathrm{yr}$. It is assumed that a cogeneration system should provide heat for process at the level of $90 \%$ of energy provided by natural gas $(32,010,458.83 \mathrm{kWh} / \mathrm{yr})$. The facility operates an average of 8,760 hours per year.

Table 1

Calculated LCA inventory indicators

\begin{tabular}{|c|c|c|c|c|c|c|}
\hline $\begin{array}{l}\text { AV } \\
\text { No. }\end{array}$ & $\begin{array}{c}\text { Elec. } \\
\text { energy } \\
\text { consumption } \\
(\mathrm{kWh} / \mathrm{yr})\end{array}$ & $\begin{array}{l}\text { Natural gas } \\
\text { consumption } \\
(\mathrm{kWh} / \mathrm{yr})\end{array}$ & $\begin{array}{l}\text { Energy } \\
\text { Savings } \\
\text { (kWh/yr) }\end{array}$ & $\begin{array}{c}\text { Estimated } \\
\text { Savings }(\$ / y r)\end{array}$ & $\begin{array}{l}\text { Implement } \\
\text { ation } \\
\text { Cost (\$) }\end{array}$ & $\begin{array}{l}\text { Electricity } \\
\text { production } \\
\text { (kWh/year) }\end{array}$ \\
\hline $\mathrm{V \# 1}$ & 289,600 & $38,147,888.92$ & $2,897,600$ & $67,571.20$ & 206,250 & $2,245,152$ \\
\hline $\mathrm{V} \# 2$ & $2,434,592$ & $3,891,608,680.92$ & $2,434,592$ & $104,330.84$ & 393,600 & $2,865,408$ \\
\hline V\#3 & $1,823,072$ & $39,530,551.34$ & $1,823,072$ & $143,337.85$ & 477,600 & $3,476,928$ \\
\hline
\end{tabular}




\subsection{Factory process flow}

Within the lumber production process, major energy consuming equipment are electrical cutter and planer, grading machines and lighting, taking into consideration natural gas there are boiler and facility heating. In this study technology assessment will be carried out for alternative energy scenarios of cogeneration systems.

After receiving raw hardwood lumber and then keeping in the storage, the lumbers are dried in kilns outside air heated by steam for about a month. Then, the hardwood lumbers are cut and planed into uniform pieces. Finally, these lumbers will be graded, sorted, packaged and shipped to customers. A process flow is depicted in Fig 2.

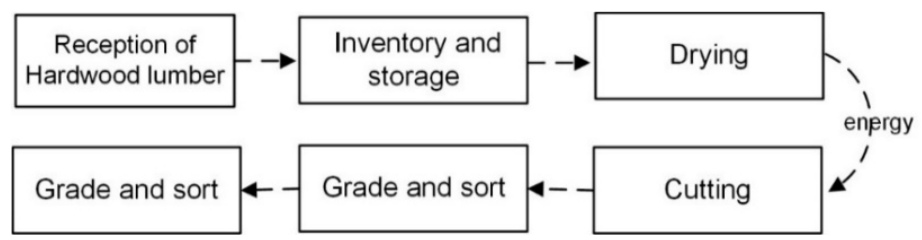

Fig. 2. Hardwood lumber process flow

Besides that the facility uses various technologies, an idea is to reduce energy impact through the adoption of technical improvements through cogeneration system or combined heat and power (CHP) in hardwood lumber process is presented in this paper.

\subsection{Identification and calculation of LCA-based indicators}

Indicators are identified from the literature review on LCA-based sustainability energy indicators. Table 2 provides LCA-based indicators that are used for sustainability assessment of alternative scenarios for cogeneration systems.

\section{Table 2}

Identification and calculation of LCA-based assessment indicators

\begin{tabular}{|c|c|c|}
\hline $\begin{array}{c}\text { Energy impact } \\
\text { category }\end{array}$ & Description & Indicators \\
\hline $\begin{array}{l}\text { Energy intensity / } \\
\text { production } \\
\text { [kWh/meter], }\left(\mathrm{I}_{\mathrm{E} 1}\right)\end{array}$ & $\begin{array}{l}\text { Total energy consumption includes the energy demand expressed } \\
\text { in functional unit [kWh/production in meter], taking the net natural } \\
\text { gas and electricity-energy consumed to provide the heat and power } \\
\text { requirements for the hardwood lumber process into consideration. }\end{array}$ & $\begin{array}{l}V \# 1=15.1453 \\
V \# 2=15.2538 \\
V \# 3=15.3971\end{array}$ \\
\hline $\begin{array}{l}\text { GWP, } \\
\left.\text { [kgCO2e/meter], (l } \mathrm{E}_{\mathrm{E} 2}\right)\end{array}$ & $\begin{array}{l}\text { Greenhouse gas emissions measure carbon dioxide per kWh of } \\
\text { energy consumed. For calculation of the amount of } \mathrm{CO}_{2} \text { emitted } \\
\text { from burning of fuel needed to generate the energy for the process } \\
\text { within production systems (Schwarz et al., 2002), the Simple } \\
\text { Carbon Calculator is used (http://www.carbon-calculator.org.uk/). }\end{array}$ & $\begin{array}{l}\mathrm{V \# 1}=3.4672 \\
\mathrm{V \# 2}=5.0820 \\
\mathrm{V \# 3}=0.5539\end{array}$ \\
\hline $\begin{array}{l}\text { LCOE [\$US/kWh], } \\
\left(\mathrm{I}_{\mathrm{E} 3}\right)\end{array}$ & $\begin{array}{l}\text { Levelized Cost of Electricity (LCOE) measures lifetime costs divided } \\
\text { by energy production. Calculates present value of the total cost of } \\
\text { technology and its operation and maintenance over an assumed } \\
\text { lifetime [DOE, 2018]. } \\
\qquad \text { LCOE }=\frac{\text { Sum of costs ober lif etime }}{\text { sum of electricity produced over lifetime }}\end{array}$ & $\begin{array}{l}V \# 1=0.0919 \\
V \# 2=0.1374 \\
V \# 3=0.3667\end{array}$ \\
\hline $\begin{array}{l}\text { Net benefit } \\
\text { [\$US/meter], (IE4) }\end{array}$ & $\begin{array}{l}\text { Net benefit [USD } \$ \text { ] is expressed as a reduced energy cost } \\
\text { (difference in annual energy cost from the baseline) over expected } \\
\text { life of new equipment ( } 25 \text { years) - equipment cost (see Table 1). } \\
\text { The calculation is not included in this paper. }\end{array}$ & $\begin{array}{l}V \# 1=-0.0483 \\
V \# 2=0.5190 \\
V \# 3=0.7278\end{array}$ \\
\hline $\begin{array}{l}\text { Energy per employee- } \\
\text { year per total annual } \\
\text { production } \\
{[\mathrm{kWh} / \text { meter }],\left(\mathrm{I}_{\mathrm{E} 5}\right)}\end{array}$ & $\begin{array}{l}\text { The unit energy consumption of the considered plant is calculated } \\
\text { as the ratio between the final energy consumption per unit of annual } \\
\text { production in meters and the number of employees created with } \\
\text { duration of one year. }\end{array}$ & $\begin{array}{l}\mathrm{V \# 1}=0.3365 \\
\mathrm{V \# 2}=0.3390 \\
\mathrm{V \# 3}=0.3422\end{array}$ \\
\hline
\end{tabular}




\subsection{Alternative technologies}

The paper depicts three alternative scenarios of investment decisions in technology LCAbased evaluation in the company operating in hardwood lumber: (existing system; variant\#1) purchase a step down turbine by operating at a 150 PSIG pressure boiler; (variant\#2) purchase a new boiler with a 300PSIG pressure and a new turbine; (variant\#3) purchase a new boiler with a 600 PSIG pressure and a new turbine.

Baseline scenario uses a heating system containing two natural gas-fired boilers. The boilers can operate up to 150 psig pressure, and the second boiler is used as a backup boiler. The energy is transferred from the boiler to the turbine through high-pressure steam that in turn powers the turbine and generator. Generator heats up when it produces electricity.

A planned cogeneration system treated as impact scenario will capture this heat and use it to regulate a heat water. In CHP system, steam at lower pressure is extracted from the steam turbine and used directly or is converted to other forms of thermal energy. Recommended CHP could be installed to produce electricity and to offset the process thermal load, currently supplied by the boiler operating up to 150 psig pressure, as presented in Figure 3 .

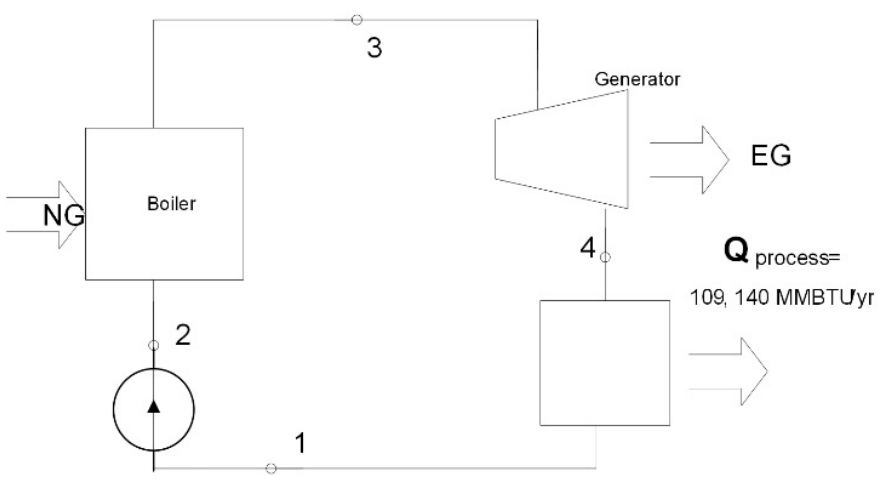

NG- natural gas; EG-electricity generated

Fig. 3. Current cogeneration system

\subsection{LCA-based Technology Sustainability Assessment}

This graphical triangle allows combining environmental performance indicators with economic and social dimensions $(\mathrm{AB} / \mathrm{BC} / \mathrm{AC})$ into an energy sustainability performance (indicator) in terms of technology named as an EnSUS index. Due to the usage of not unitary form of different sustainability indicators of various magnitudes provides, normalized score for each dimension is required, taking the total values for each dimension for each alternative technology as the length of vectors corresponding indicators. Environmental dimension is characterized by a set of indicators of various units designated by environmental indicators le1, $\mathrm{I}_{\mathrm{E} 2}$, for economic indicators by $\mathrm{I}_{\mathrm{E} 3} \mathrm{I}_{\mathrm{E} 4}$, and social dimension - $\mathrm{I}_{\mathrm{E} 5}$.

The plot compares also the results of each impact are normalized, resulting in a scale from 0 to 1. Each impact (environmental, economic, and social) represents a combination of its indicators which are normalized, e.g. environmental performance is calculated as the length of vectors of indicators, expressed by the equation (1) (Ryan, 2015):

$$
I_{E N V}=A B=\sqrt{\left(I_{E 1}{ }^{2}+I_{E 2}{ }^{2}\right)}
$$

The area between dimensions positioned on a triangle represents the LCA-based technology sustainability performance impact, EnSUS. The normalization of these indicators for environmental sustainability. The economic (BC) and social dimensions (AC) are normalized in the same way. More details how to calculate the area of triangle $A B C$ was express in an equation (2), (Lucato, 2017):

$$
\text { EnSUS }=(A B+A B+B C) / 2
$$


The mixture of the three dimensions can be summarized by a point (with value 1 ) in the triangular coordinate system defined by the indicators.

\section{RESULTS}

The results showed that, based on the assessment of five sustainability criteria in this research, installation of the third option $(\mathrm{V} \# 3)$ for cogeneration system is the most recommended (Table 3). The outcomes of the study pictured on the triangle revealed that the cogeneration system with a new boiler with a 600 PSIG pressure and a new turbine seems to be a cost-efficient solution compared to the baseline scenario saving energy at the level of $1,823,072 \mathrm{kWh} / \mathrm{yr}(63 \%)$. In the case study, the implemented solution in the plant improved the overall sustainability degree of technology by 53 (from 46 as baseline to 97). Results from various CHP can be compared in a ternary plot where the percentage of each dimension is plotted on the three axes as shown in Figure 4 and Table 3.

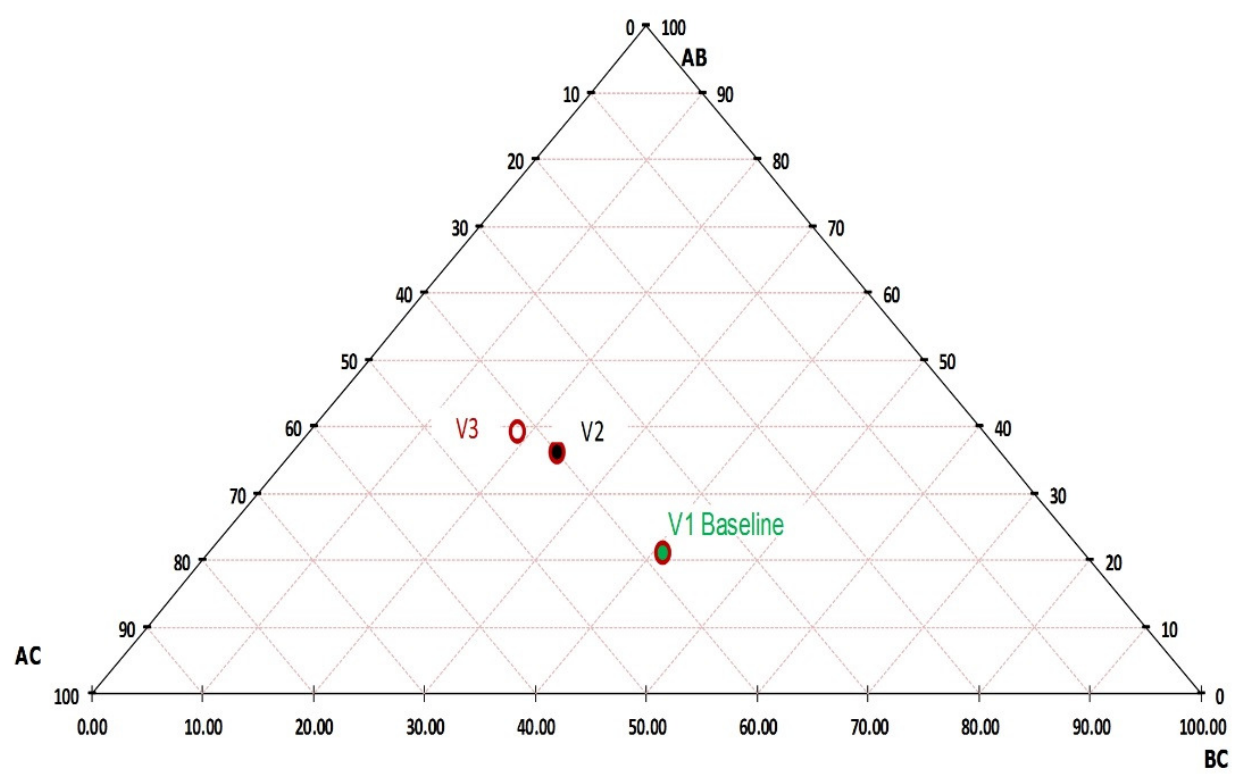

Fig. 4. Assessment triangle of technology sustainability

Table 3

Normalized values for CHP technologies in terms of three-dimension performances

\begin{tabular}{|c|c|c|c|c|}
\hline & AB & BC & AC & EnSUS index \\
\hline V\#1 & 21.00 & 41.00 & 38.00 & 0.458 \\
\hline V\#2 & 36.00 & 24.00 & 40.00 & 0.786 \\
\hline V\#3 & 39.00 & 19.00 & 42.00 & 0.974 \\
\hline
\end{tabular}

The proposed cogeneration systems increased the levelized costs of energy the 5 years by $10 \%$ with a tendency to decreasing over the next 20 years (Figure 5 ). Because the designed CHP with $398 \mathrm{~kW}$ capacity requires more fuel for a given energy output, the use of the cogeneration systems increase the demand on natural gas, and reduce energy costs associated with providing heat to a facility.

Automatically, a reduction in the quantities of $\mathrm{CO}_{2}$ associated with energy use is possible up to $16 \%$ compared to the baseline scenario. Improvements in the efficiency of technologies and devices have facilitated continuing reductions in maintenance and operations costs as well as the quantity of energy required to produce a unit of goods in industrial plants. 


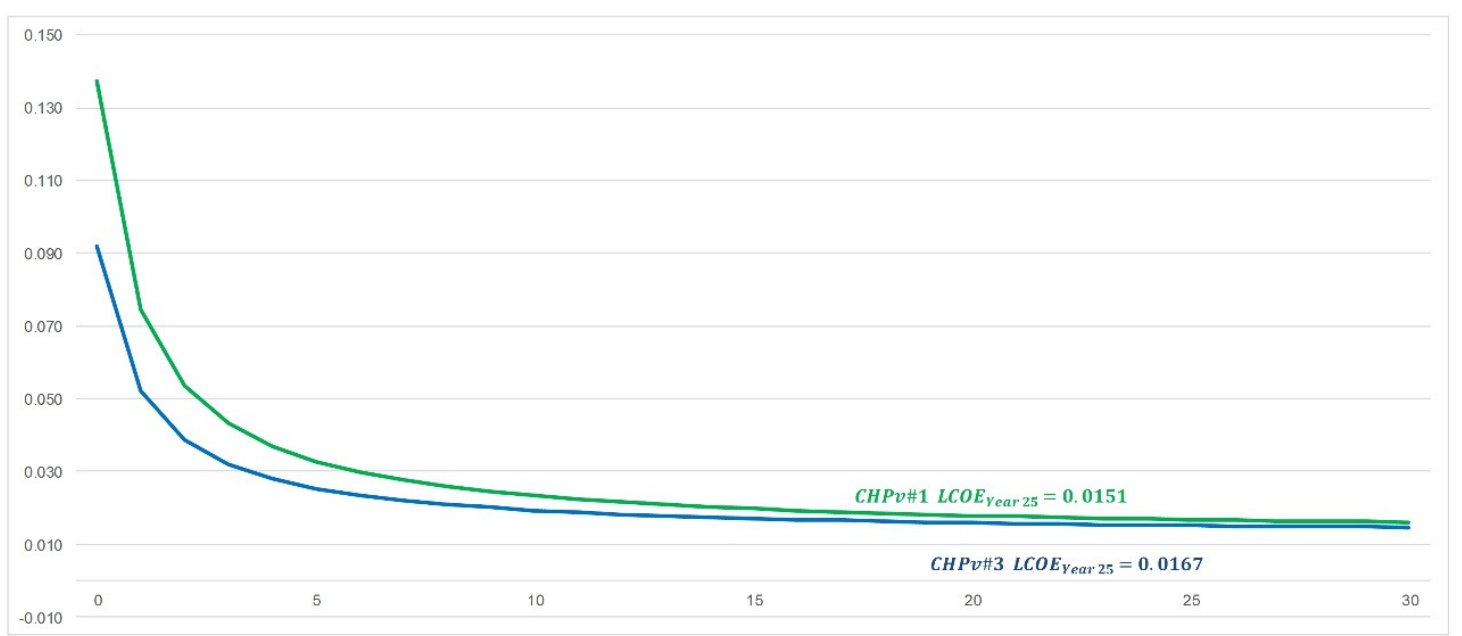

Fig. 5. LCOE $[\$ / \mathrm{kWh}]$ over Lifetime [Years]

\section{CONCLUSIONS}

The results picture that, based on the normalized LCA-based indicators in terms of three sustainability issues applied in this work, the third recommendation, with energy savings at the level of $1,823,072 \mathrm{kWh} / \mathrm{yr}(63 \%)$ seems to be a cost-efficient solution compared to the baseline scenario $(2,897,600 \mathrm{kWh} / \mathrm{yr})$. As a recommended action to improve energy efficiency in the plant, the cogeneration system could be installed to produce electricity and to offset the process thermal load, currently supplied by the boiler operating up to 150 psig pressure. Taking into consideration of the three variants, cogeneration systems require more natural gas, but due to own electricity generation, overall utility cost are reduced by appropriately.

The effort to improvement of this technology guides to the transition into technology sustainability pathway. However, estimated energy cost savings envisaged to be achieved by the implementation of the new boiler with a 600 psig pressure and a new turbine.

The map provides an overall indicator of the sustainable performance for each CHP technology allowing the comparison of different technologies of unequal life spans, different investment cost, and capacities.

\section{DISCUSSION}

As seen in the paper, the most sustainable technology options are those with higher energy efficiency operations. Overall, two variants are energy efficient comparing the baseline scenario (variant \#1). Based on the findings, it is necessary to take two actions: (1) make trade-off among the sustainability criteria which can be easily explored within the decisionsupport framework to reveal how different decision-makers preferences affect the outcomes of sustainability assessment what was as outlined by Santoyo-Castelazo and Azapagic (2014). This framework, thus, will help pursuing projects on an economic basis, in turn, proceeding with development of a facility or commercial-scale project. Actions to select criteria seem to be elementary but have the potential to become usefulness if combined with the other making decision methods thus that could offer benefits for more intensive energy efficiency improvement. The results regarding the investment process would have been strengthened if operational managers had also been included in the analysis and assessment process; (2) provide energy management program to continue account of energy use and its cost. This can be developed by keeping up-to-date records of monthly energy consumption and associated costs.

The study revealed that a way of reducing the environmental impact and suggests an approach for assessment and further the implementation of cost-efficient and energy saving technology which can be applied in various manufacturing units. 
A few limitations of this study should be noted because of the quality of the data which may contain errors on human's level. Data was derived from energy audits conducted, and these audits may have measurement errors. On the other hand, data related to potential cost and energy saving was aggregated and thus may have a worse quality. The methodology is based on technology assessment as whole, focusing on designed sustainability criteria. This calculation of potential economic benefits expected to be achieved is initial, and assumes that an outside plant will provide the equipment and installation. If, for example, plant's staff could provide installation support to the project, the cost may be significantly less. The visualization of the research allows comparing energy technologies and it could be an insight for decision-makers in future.

\section{REFERENCES}

Armina, E. and Vilsi, A. L. (2015). Key Performance Indicators for Sustainable Manufacturing Evaluation in Cement Industry. Procedia CIRP, 26, pp. 19-25.

De Benedetto, L., Klemes, J. (2009). The Environmental Performance Strategy Map: an integrated LCA approach to support the strategic decision-making process. Journal of Cleaner Production, 17, pp. 900-906.

Da Silva, P. R. S. and Amaral, F. G. (2009). An integrated methodology for environmental impacts and costs evaluation in industrial processes. Journal of Cleaner Production, 17(15), pp. 1339-1350.

DOE, (2018). Levelized Cost of Energy (LCOE). [online] Available at: https://www.energy.gov/sites/prod/files/2015/08/f25/LCOE.pdf/ [Accessed 23 Apr. 2018].

Kluczek, A. (2018). Dynamic energy LCA-based assessment approach to evaluate energy intensity and related impact for the biogas CHP plant as the basis of the environmental view of sustainability. Procedia Manufacturing

Lindberg, C., Tan, S. T.; Yan, J. Y. and Starfelt, F. (2015). Key performance indicators improve industrial performance. Energy Procedia, 75, pp. 1785 - 1790.

Lucato, W.C. (2018). Measuring the sustainability of a manufacturing process: A conceptual framework. Sustainability, 10(1), pp. 81.

Ness, B., Urbel-Piirsalu, E., Anderberg, S. and Olsson, L. (2007). Categorizing tools for sustainability assessment. Ecological Economics, 60(3), pp. 498-508.

Ryan, M. (2015). Geometry for Dummies. New York, NY: For Dummies Book.

Santoyo-Castelazo, E. and Azapagic, A. (2014). Sustainability assessment of energy systems: integrating environmental, economic and social aspects. Journal of Cleaner Production, 80, pp. 119-138.

Skowrońska, M. and Filipek, T. (2014). Life cycle assessment of fertilizer: review. International Agrophysics, 28, pp. 101-110. 